\title{
The Alignment of IT and Business Strategy at ROC Leeuwenborgh by Leo Santoso
}

Submission date: 10-Oct-2019 06:25PM (UTC+0700)

Submission ID: 1189972603

File name: ICSIIT_2017_Full_Paper.pdf (733.87K)

Word count: 5497

Character count: 37024 
Proceedings

\title{
2017 International Conference on Soft Computing, Intelligent System and Information Technology ICSIIT 2017
}

\author{
Denpasar, Bali, Indonesia
}

26-29 September 2017

Edited by

Henry Novianus Palit and Leo Willyanto Santoso






\section{International Conference on Soft Computing, Intelligent System and Information Technology \\ ICSIIT 2017}

Table of Contents

Preface.

Conference Organization.. xii

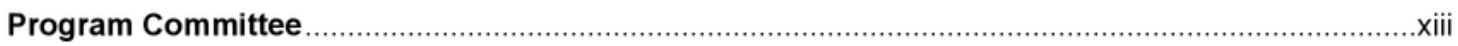

Reviewers

..$x v$

\section{Classification and Correlation Techniques}

Gesture Recognition for Indonesian Sign Language Systems (ISLS) Using

Multimodal Sensor Leap Motion and Myo Armband Controllers Based

on Naîve Bayes Classifier

Khamid, Adhi Dharma Wibawa, and Surya Sumpeno

Waah: Infants Cry Classification of Physiological State Based on Audio

Features

Ramon L. Rodriguez and Susan S. Caluya

Fuzzy Clustering and Bidirectional Long Short-Term Memory for Sleep Stages

Classification

Intan Nurma Yulita, Mohamad Ivan Fanany, and Aniati Murni Arymurthy

MFCC Feature Classification from Culex and Aedes Aegypti Mosquitoes Noise

Using Support Vector Machine

Achmad Lukman, Agus Harjoko, and Chuan-Kay Yang

Automatic Chord Arrangement with Key Detection for Monophonic Music

Bor-Shen Lin and Ting-Chun Yeh

Credit Scoring Refinement Using Optimized Logistic Regression

Hendri Sutrisno and Siana Halim

Anomaly Detection System Based on Classifier Fusion in ICS Environment. 32

Jan Vávra and Martin Hromada 
Ryo Kawanami and Kousuke Matsushima

\section{Feature Extraction and Image Recognition Methods}

Timor Leste Tais Motif Recognition Using Wavelet and Backpropagation

Vasio Sarmento Soares, Albertus Joko Santoso, and Djoko Budyanto Setyohadi

The Model and Implementation of Javanese Script Image Transliteration

Anastasia Rita Widiarti, Agus Harjoko, Marsono, and Sri Hartati

Human Activity Recognition by Using Nearest Neighbor Algorithm from Digital

Image

Muhammad Ihsan Zul, Istianah Muslim, and Luqman Hakim

Night to Day Algorithm for Video Camera

Stefan Jack Lionardi, Mariëlle Fransen, and Andreas Handojo

Arca Detection and Matching Using Scale Invariant Feature Transform (SIFT)

Method of Stereo Camera

Aviv Yuniar Rahman, Surya Sumpeno, and Mauridhi Hery Purnomo

The Application of Deep Convolutional Denoising Autoencoder for Optical

Character Recognition Preprocessing

Christopher Wiraatmaja, Kartika Gunadi, and Iwan Njoto Sandjaja

Acne Segmentation and Classification Using Region Growing

and Self-Organizing Map

Gregorius Satia Budhi, Rudy Adipranata, and Ari Gunawan

\section{Algorithms for Intelligent Computation}

Extended Concept of Generalized Fuzzy Rough Sets on Asymmetric Fuzzy

Coverings

Rolly Intan

The Proposal of the Software for the Soft Targets Assessment

Lucia Duricova, Martin Hromada, and Jan Mrazek

Application of Artificial Intelligence (AI) in Search Engine Optimization (SEO)

Yodhi Yuniarthe

Spatial Model Design of Landslide Vulnerability Early Detection

with Exponential Smoothing Method Using Google API

Kristoko Dwi Hartomo, Sri Yulianto, and Joko Ma'ruf

Measures of Dependency in Metric Decision Systems and Databases

Anh Duy Tran, Somjit Arch-int, and Ngamnij Arch-int

Multiple Scattered Local Search for Course Scheduling Problem .

Ade Jamal 
The Software Proposes for Management and Decision Making at Process

Transportation

Jan Mrazek, Lucia Duricova, and Martin Hromada

\section{Distributed Systems and Computer Networks}

A Self-Adaptive Architecture with Energy Management in Virtualized

Environments

I Made Murwantara, Behzad Bordbar, and João Bosco Ferreira Filho

Nanoservices as Generalization Services in Service-Oriented Architecture

Sutrisno, Frans Panduwinata, and Pujianto Yugopuspito

Automated Concurrency Testing for Cloud-Based Polling Systems

Hans Dulimarta

Low-Overhead Multihop Device-to-Device Communications in Software

Defined Wireless Networks

Riyanto Jayadi and Yuan-Cheng Lai

A Secure Anonymous Authentication Scheme for Roaming Service in Global

Mobility Network

Kuo-Yang Wu, Yo-Hsuan Chuang, Tzong-Chen Wu, and Nai-Wei Lo

Linux PAM to LDAP Authentication Migration 155

Justinus Andjarwirawan, Henry Novianus Palit, and Julio Christian Salim

Exploratory Research on Developing Hadoop-Based Data Analytics Tools 160

Henry Novianus Palit, Lily Puspa Dewi, Andreas Handojo, Kenny Basuki,

and Mikiavonty Endrawati Mirabel

\section{Mobile and Pervasive IoT Applications}

Human Heart Rate Detection Application

Semuil Tjiharjadi and Aufar Fajar

Near Field Communication Technology in Delivering Information in Museums

Djoni Haryadi Setiabudi, Ryan Christian Wiguno, and Henry Novianus Palit

Android Application for Monitoring Soil Moisture Using Raspberry Pi

Lily Puspa Dewi, Justinus Andjarwirawan, and Robin Putra Wardojo

Development of Mobile Indoor Positioning System Application Using Android

and Bluetooth Low Energy with Trilateration Method

Agustinus Noertjahyana, Ignatius Alex Wijayanto, and Justinus Andjarwirawan 


\section{Assessments of Integrated IS/IT}

The Proposal of United Crisis Management Information Systems of the Czech

Republic

Katerina Vichova, Martin Hromada, and Ludek Lukas

The Analysis of Academic Information System Success: A Case Study

at Instituto Profissional De Canossa (IPDC) Dili Timor-Leste

Apolinario Dos Santos, Albertus Joko Santoso, and Djoko Budiyanto Setyohadi

Identification of Factors Influencing the Success of Hospital Information

System (SIRS) by Hot-Fit Model 2006: A Case Study of RSUD Dr

Samratulangi Tondano, Minahasa Regency, North Sulawesi

Frendy Rocky Rumambi, Albertus Joko Santoso, and Djoko Budyanto Setyohadi

The Alignment of IT and Business Strategy at ROC Leeuwenborgh

Frederick Wonges, Jack Zijlmans, and Leo Willyanto Santoso

Development of Capability Assessment Model of IT Operation Management

Process with Organizational Behavior

Luh Made Wisnu Satyaninggrat and Kridanto Surendro

Exploring Critical Success Factors of Mobile Learning as Perceived

by Students of the College of Computer Studies - National University

Bernie S. Fabito

Identifying Characteristics and Configurations in Open Source ERP

in Accounting Using ASAP: A Case Study on SME

Agung Terminanto and Achmad Nizar Hidayanto

\section{Simulation and Virtual Reality Applications}

The Real Time Training System with Kinect: Trainer Approach

Ivana Valentine Masala and Apriandy Angdresey

3D LIDAR City Model Application and Marketing Plan Development

Kevin Sanjaya, Frank Henning, and Kristo Radion Purba

Periodic Review Inventory Model Simulations for Imperfect Quality Items

and Stochastic Demand.

Gede A. Widyadana, Audrey T. Widjaja, and Irena Liong

Simulation on Crowd Mobility of Moving Objects Using Multi-agent

and ClearPath

Baihaqi Siregar, Agnes Irene Silitonga, Erna Budhiarti Nababan, Ulfi Andayani,

and Fahmi Fahmi

Truck Management Integrated Information System in a Shipping Line

Company

Arnold Samuel Chan and I Nyoman Sutapa 
Simulation of Atmosphere in Trowulan during the Golden Era of Majapahit

Using Virtual Reality

Daniel Kusuma, Rudi Adipranata, and Erandaru

Development of Interactive Learning Media for Simulating Human Digestive

System

Kristo Radion Purba, Liliana, and Daniel Runtulalu

Development of Interactive Learning Media for Simulating Human Blood

Circulatory System

Kristo Radion Purba, Liliana, and Yohanes Nicolas Paulo Kwarrie

\section{Smart Assistive Technologies}

Fall Detection Application Using Kinect

Kartika Gunadi, Liliana, and Jonathan Tjitrokusmo

Driver Drowsiness Detection Using Visual Information on Android Device

Aldila Riztiane, David Habsara Hareva, Dina Stefani, and Samuel Lukas

Epileptic Alert System on Smartphone

Aziis Yudha Adwitiya, David Habsara Hareva, and Irene Astuti Lazarusli

Elderly Healthcare Assistance Application Using Mobile Phone

Andreas Handojo, Tioe Julio Adrian Sutiono, and Anita Nathania Purbowo

Socially-Enhanced Variants of Mobile Bingo Game: Towards Personalized

Cognitive and Social Engagement among Seniors

Chien-Sing Lee, Shanice Wei-Ling Chan, and Sheng-Yee Guy

\section{Smart Mobile Applications}

M-Guide: Hybrid Recommender System Tourism in East-Timor

Jaime da Costa Lobo Soares, Suyoto, and Albertus Joko Santoso

M-Guide: Recommending Systems of Food Centre in Buleleng Regency

Komang Ananta Wijaya, Suyoto, and Albertus Joko Santoso

Empowering Public Secondary Schools on Disaster Response and Recovery:

A Framework for the Development of Helpline Mobile Application

Odette Saavedra, Matthew C. Abrera, Mickaela Carla L. Waniwan,

Curly Kale C. Dava, and Bernie S. Fabito

A Framework Mobile Game Application that Teaches Parts of Speech

in Grade 3 in Filipino

John Erasmus Correa, Jastine Gamboa, Mark Edison Lavapie, Edzel Uy,

and Ramon L. Rodriguez

iSagip: A Crowdsource Disaster Relief and Monitoring Application Framework

Auxesis Jacobi M. Schwab, John Eduard C. Omaña, Kent V. Roazol,

Ted Anthony Y. Abe, and Bernie S. Fabito 


\section{Case Studies of Knowledge Discovery and Management}

Executive Dashboard as a Tool for Knowledge Discovery

Nyoman Karna

Data Mining Applications for Sales Information System Using Market Basket

Analysis on Stationery Company

Alexander Setiawan, Gregorius Satia Budhi, Djoni Haryadi Setiabudi,

and Ricky Djunaidy

A Knowledge Management-Extended Gamified Customer Relationship

Management System

Chien-Sing Lee, Jun-Jie Foo, Vinudha a/p Jeya Sangar, Pei-Yee Chan,

Weng-Keen Hor, and Eng-Keong Chan

Web Based Customer Relationship Management Application for Helping Sales

Analysis on Bike Manufacturer

Anita Nathania Purbowo, Yulia, and Agustinus Ivan Suryadi

Replenishment Strategy Based on Historical Data and Forecast of Safety

Stock

Allysia Ongkicyntia and Jani Rahardjo

On Estimation and Prediction of Simple Model and Spatial Hierarchical Model

for Temperature Extremes.

Indriati Njoto Bisono

Author Index 


\section{The Alignment of IT and Business Strategy at ROC Leeuwenborgh}

\author{
Leo Willyanto Santoso \\ . nformatics Department \\ Petra Christian University \\ Siwalankerto 121 - 131 Surabaya \\ 60236, Indonesia \\ leow@petra.ac.id
}

\author{
Jack Zijlmans \\ Business Information System \\ Fontys University of Applied Sciences \\ Rachelsmolen 1, 5612 MA Eindhoven, \\ The Netherlands \\ j.zijlmans@fontys.nl
}

\author{
Frederick Wonges \\ Business Information System \\ Petra Christian University \\ Siwalankerto 121 - 131 Surabaya \\ 60236, Indonesia \\ frederickwonges@gmail.com
}

\begin{abstract}
The alignment of IT and business strategy plays important role to achieve company goals. Indeed, the business and IT performance are tightly coupled, and company cannot be competitive if their business and IT strategies are not aligned. ICT Lyceum ROC Leeuwenborgh tends to have IT strategic plan as a guideline to aligned between IT and business strategy. The main goal of this research is to make a recommendations for the new IT strategy implementation as a part of EA that can support the business goals. In order to create the recommendation, Strategic Information System Planning with Ward and Peppard method has been used. The internal (strengths and weaknesses) and external (opportunities and threats) factors of business and IT of ICT Lyceum have been analyzed based on Applegate L.M. perspective. The perspective contains 3 models analysis: Porter's Five Forces, McFarlan Strategic Grid, and Strategic Alignment. Afterward, the strengths, weaknesses, opportunities, and threats were put into a TOWS matrix in order to create the strategies options. Strategies options were being used to create the recommendations of information technology in hardware and software. The findings of the study show that ROC Leeuwenborgh perceive that alignment is important and can bring considerable benefits.
\end{abstract}

Keywords-Alignment; IT strategy; IS Strategic Planning; Ward and Peppard; SWOT.

\section{INTRODUCTION}

Alignment between business and IT is a condition where the vision, mission, value, objective, and planning within business strategy are supported by IT. Achieving this stage has long been a critical issue for many organisations in the world.

The previous research showed the importance of alignment if organizational success is to be achieved [1, 2] IT became seen to be a part of organisations [3, 4]. Small and medium enterprises (SME) also get the positive IT impact on organisational performance [5]. SMEs with high level of business-IT alignment indicate better performance than SMEs with low level business-IT alignment [6]. There is a positive relationship between business-IT alignment and organisational performance based on strategic perspective [7].
Nowadays, IT has become an important aspect of everyday business [8]. Business-IT alignment has shown to increase organisation profit and performance $[9,10]$. It also improves the return on investment for Information Systems $[11,12]$.

ROC (Regionaal Opleidingen Centrum) Leeuwenborgh tend to improve their performance and profit. ROC Leeuwenborgh is an MBO education in The Netherlands which provides educational in $\mathrm{CUvV}$ (CIOS, Skin Care, Safety), education, Healthcare and Welfare, economic, and technology. Due to the students are in the range of 16 years old until 21 years old, this education is purposed not only teach them with knowledge, but also a place for them to grow, search, and build their identity.

On the other side, Information technology (IT) infrastructure lies at the heart of most companies' operating capabilities. Because ICT Lyceum, one of the departments in economy sector, which giving an IT education, depends on these technologies, no longer is IT simply nice to have; no longer is IT just value-adding. It has become vital.

From those two points stated above, there is similarity that can be seen as opportunities, where ICT Lyceum can provide the right IT infrastructure for their customers (students, teachers, and managements), ICT Lyceum can improve their customer's satisfaction. IT infrastructure can consist of seven sectors, which are: the hardware, the software, the data storage, the network, the internet, the integrated system and the operating system. When ICT Lyceum has a guidelines or strategies to be executed in the IT infrastructure, ICT Lyceum can also control its cost. The other point is that when ICT Lyceum can offer the newest technology, it can expand the market. The conclusion is that ICT Lyceum department wants to improve its IT infrastructure in hardware and software.

The output of this research is mainly to give recommendations of IT infrastructure support, such as hardware, software and network component to align the IT and the Business based on customer (students, teachers, and managements) needs to support the strategic company business goals. The deepest challenges of IT management are in understanding and assigning responsibility for making 
these just not technical, not just business decisions, in bridging the gap between the business and technology domain.

The rest of the paper is organised as follows. Section 2 discusses the literature review that focused on business-IT alignment models. Section 3 describes the research methodology. The next section presents the results of the survey and discusses their implications. The final section concludes the paper and presents some suggestions for future work.

\section{STRATEgIC INFORMATION SYSTEM PLANNING}

Strategic Information System Planning is the procedure used to create a strategy. Strategic Information System Planning was chosen because it is giving an assistance for the company to identify and to align company's strategy with effective information systems to achieve company's objectives [13]. Ward \& Peppard method is being used to make the Strategic Information System Planning. The method of Ward \& Peppard can be seen in Fig. 1. In the Ward \& Peppard method, there are business and information technology internal and external factors that need to be analyzed. Both factors are analyzed by using Applegate L.M. [14] perspective that can be seen in Table 1. The perspective also contains 3 model analysis: Porter's Five Forces, McFarlan Strategic Grid, and Strategic Alignment. For business factors, the analyzed is incorporated into SWOT (Strengths, Weaknesses, Opportunities, and Threats) analysis. Afterward, the SWOT analysis were put into a TOWS matrix in order to create the strategies options. Strategies options were being used to create the recommendations of information technology in hardware and software.

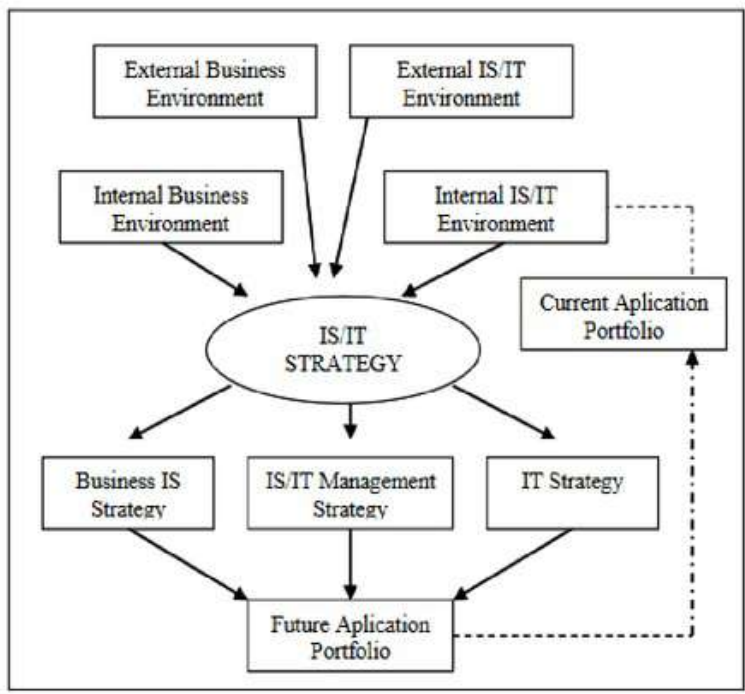

Figure 1. Ward \& Peppard Method [13]
TABLE I. APPlegate L.M. Perspective

\begin{tabular}{|c|c|c|c|}
\hline Perspec-tive & Description & Factor & Analysis \\
\hline 1 & IT and Strategy & \multirow{6}{*}{ Business } & \\
\hline 2 & $\begin{array}{l}\text { The organization as a case } \\
\text { for IT }\end{array}$ & & External \\
\hline 3 & IT and Organization & & \multirow{4}{*}{ Intemal } \\
\hline 4 & $\begin{array}{l}\text { Infrastructure and } \\
\text { Operations }\end{array}$ & & \\
\hline 5 & $\begin{array}{l}\text { Organizing and Leading } \\
\text { the IT Function }\end{array}$ & & \\
\hline 6 & $\begin{array}{l}\text { A Portfolio Approach to } \\
\text { Managing IT Projects }\end{array}$ & & \\
\hline 7 & \multirow{2}{*}{$\begin{array}{l}\text { Extending the Enterprise } \\
\text { Internetworking } \\
\text { Infrastructure }\end{array}$} & \multirow[b]{2}{*}{ IT } & Extemal \\
\hline 8 & & & Intemal \\
\hline
\end{tabular}

\section{METHODOLOGY}

The first phase of this research is initiation. This phase is to plan for the whole research workflow. Planning is essential to keep the research on the right schedule. Creating a research plan and gathering information about requirements of the research are done in this phase. The second phase is research. The research methodology is using DOT framework that can be seen in Fig. 2. The information will be gathered using 5 different methods which are: Library, Field, Workshop, Lab, and Showroom. The third phase is analyzing \& writing. This phase is to analyze all the information that gained from research phase to make the recommendation of IT strategy. The last phase is delivery. This phase is to deliver the report that contain the recommendation of IT strategy.

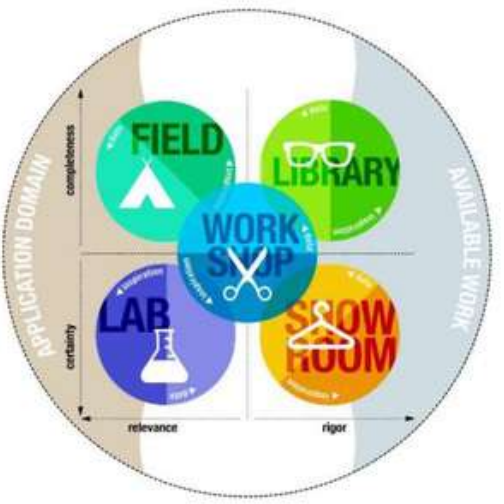

Figure 2. DOT Framework [15]

\section{RESULT AND DISCUSSION}

The various observation based on perspectives in Table 1 are provided below.

\section{A. Perspective 1: IT and Strategy}

The various observations showed that ICT Lyceum offered the right courses at the right time on product 
positioning. Information technology especially application and media are growing nowadays. The values to have based knowledge, self-learning and good motivation are leading. Therefore students can improve their knowledge by themselves in the future. The department also focuses on improving the IT environment especially in hardware and software to offer students the best possible service to feel the IT world.

Because of the education level is in the middle range, the market of students are wide enough. Furthermore, with collaboration with education below this range, the department can more easily reach the students. However, entering a technology sector, there is a problem when ICT Lyceum can not provide the great and the updated technology for their students. Offering the great and updated technology offers an opportunity to generate new revenue from new and existing students.

A second opportunity that flows is able to supply enough hardware, especially on laptops or PCs to the low-economy students. By owning sufficiency PC or laptops, students can be offered better service. The students can spend their money to buy another IT stuff rather than only to buy the expensive laptops to reach the requirement of the software. The focus of the students is not to strategic level, but the operational and managerial level of work. There is no possibility for ICT Lyceum to teach students to work at the strategic level because it is for a higher range of education.

The observation revealed that the company is working to improve the IT hardware and software in consideration of business needs, cost and efficiency. IT provision in ICT Lyceum is removed by ICT Lyceum itself. This IT provision is thus a provision which is taken by both students and teachers demand. Within the strategic grid is seen as a logical route to ultimately to the strategic quadrant. It should be noted that IT remains within the factory quadrant, but that information was then given the opportunity to develop from factory to strategic. The transition of IT to the factory quadrant is, therefore, essential to take the next step with information.

The observation shows that the company operates a business inside the chain in order to run the education in information technology sector. The business strategy act as the driver of the company and the IT field is involved in supporting the business. However, the business strategy is not $100 \%$ truly drive the infrastructure and the processes. The IT field has not chosen the infrastructure and processes, but IT field mentioned it. Therefore, high cost appears as a problem because the business field does not know exactly every year what the IT will be.

Having an IT strategy, the company could be known at least the general and the concept of the IT infrastructure and processes each year. Also, it gives benefits for both business field and IT field. On the business side, control cost could be done. On IT side, estimate the strategies are right or not could be done.

\section{B. Perspective 2: The organization as a case for IT}

The observation revealed that ICT Lyceum focused on improving leverage infrastructure to support the business. The goal is to improve the hardware network and computers which are used for examination by students. Likewise, improving the software to easier both students and teachers in both grading and survey the teacher. Besides, to make the possible transition of support and factory quadrant to strategic quadrant. The fact is a lack of time and people to realize the strategic. The result is the strategic need to be reevaluated to make sure that it is still needed in that time.

\section{Perspective 3: IT and Organization}

The internal customer which is teachers need to work together. This is a huge problem because teachers are the customer who mentioned the IT things to run the business. There are 2 possibilities to solve the case by scheduling them to discuss the IT things in the department or create one small group consisting of 3 people which focus on analyzing and improving the IT infrastructure regularly. The fact is teachers are very busy when scheduling them to think about the IT infrastructure, they will have a double job which is why to create one small group to audit the IT infrastructure at ICT Lyceum is the best choice.

\section{Perspective 4: Infrastructure and Operations}

The observations show that ICT Lyceum's data center has physically housed in the same building of the department. The data center is owned by ICT Lyceum department. Every worker can access the room because it has the same lock key as the other door. The only one ICT Lyceum control for the data center is about the temperature of the room which about 21-degree Celsius.

\section{E. Perspective 5: Organizing and Leading the IT Function}

The observations at ICT Lyceum shows that the department mainly in user dominance side. User controls the IT to run the business is the main factor ICT Lyceum goes to this side. The department also needs the IT to run their business, in another word it is fit with the company. However, managerial level wants to control the cost of the IT infrastructure. Having a central data center which connecting both ICT Lyceum locations (Sittard and Maastricht) will improve the business. Both user dominance and centralized IT structure are needed for the company, but the need is a different time. The system is based on customers demand and need to be centralized by the IT structure. The result is ICT Lyceum still work on to control the cost, making connected locations and ensuring the needed system

\section{F. Perspective 6: A Portfolio Approach to Managing IT Projects}

The observations at ICT Lyceum shows that the company after implementing projects, the department needs to prove the positive result to the strategic level. There is no 
use of certain types of project management tools that are tailored to the type of project undertaken. The projects are not planned in the framework of a program. In carrying out the project using a traditional model based on the system development life cycle (SDLC). Adaptive methods are not used. Can be inferred from the observations that the project in ICT Lyceum department is totally guided by Mr. Chris Vrolings. This is a good step that may decrease the inaccuracy time, cost, and inefficiency during the execution of projects.

\section{G. Perspective 7: Extending the Enterprise}

The observations at ICT Lyceum shows that the department is in line with the development of technology by providing lessons in the field of mobile, especially in mobile application. In term of size, there is nothing to worry because the hardware (server, router, and $\mathrm{PC}$ ) to run their business already has their own space. In software field, there has been a software for data storage based on web service.

\section{H. Perspective 8: Internetworking Infrastructure}

The observations at ICT Lyceum shows that the department uses some specific software such as Fronter to view schedule, Outlook e-mail, and attendance system. Supporting software also used in terms of learning such as Microsoft Office, CISCO, VM Ware, etcetera. For the hardware, the intended Server is only for Local Area Network (LAN) and only 1 unit using $2 x$ Intel Xeon, 164GB RAM. The 20 Personal Computers (PCs) are available for use by students. The specifications of the PC are Pentium ${ }^{\circledR}$ Dual-Core CPU E5 $500(2.7 \mathrm{GHz}, 2 \mathrm{MB}$ L2 cache), 4GB (2x2GB) DDR2 $800 \mathrm{MHz}$ SDRAM Memory.

The strengths, weaknesses, opportunities, and threats (SWOT) analysis are provided below in Table 2 .

\section{TABLE II. SWOT ANALYSIS}

\begin{tabular}{|c|c|}
\hline Strengths & Weaknesses \\
\hline $\begin{array}{l}\text { 1. There are } 2 \text { locations: Sittard } \\
\text { and Maastricht. } \\
\text { 2. There is a simple network } \\
\text { which can be easily upgraded. } \\
\text { 3. There are a lot of technical } \\
\text { teachers which understand IT } \\
\text { and network. It is easy to build } \\
\text { and improve the IT } \\
\text { infrastructures by itself. } \\
\text { 4. ICT Lyceum department can } \\
\text { build their own structure } \\
\text { separate from the company } \\
\text { (ROC Leeuwenborgh). }\end{array}$ & $\begin{array}{l}\text { 1. Data center less secure } \\
\text { because the lock key has same } \\
\text { as the others doors. } \\
\text { 2. There is no specific IT group } \\
\text { in ICT Lyceum department } \\
\text { which analysis and audit the } \\
\text { IT en vironments. } \\
\text { 3. There is no specific planned } \\
\text { when company examination } \\
\text { projects. } \\
\text { 4. Still working on having } \\
\text { centralized IT structure which } \\
\text { can be analysis and estimate } \\
\text { the cost. }\end{array}$ \\
\hline Opportunities & Threats \\
\hline $\begin{array}{l}\text { 1. Offering education at the right } \\
\text { time, IT, which means the } \\
\text { market is growing. }\end{array}$ & $\begin{array}{l}\text { 1. The market will loss when can } \\
\text { not provide the right and } \\
\text { existing technology. }\end{array}$ \\
\hline $\begin{array}{l}\text { 2. There is an opportunity to } \\
\text { work together with a lower and }\end{array}$ & $\begin{array}{l}\text { 2. Information technology moves } \\
\text { d to strategic quadrant which }\end{array}$ \\
\hline
\end{tabular}

higher education (VMBO \& improves the risk of missing $\mathrm{HBO}$ ). time

3. A chance to improve the 3. Information technology environment with the existing growing rapidly which need to technology. look for demand frequently.

4. A specific field of education. 4. Rapid demand changes and no Only focus on educating IT strategy cause a higher cost. people in the operational and managerial level.

TOWS Matrix of ICT Lyceum is shown in Fig. 3. The cross sign means that both options can help each other and be a strategy. By connecting each cross sign of TOWS Matrix, the strategic options, the related quadrant, and term to the strategic options of ICT Lyceum can be seen in Table 3.

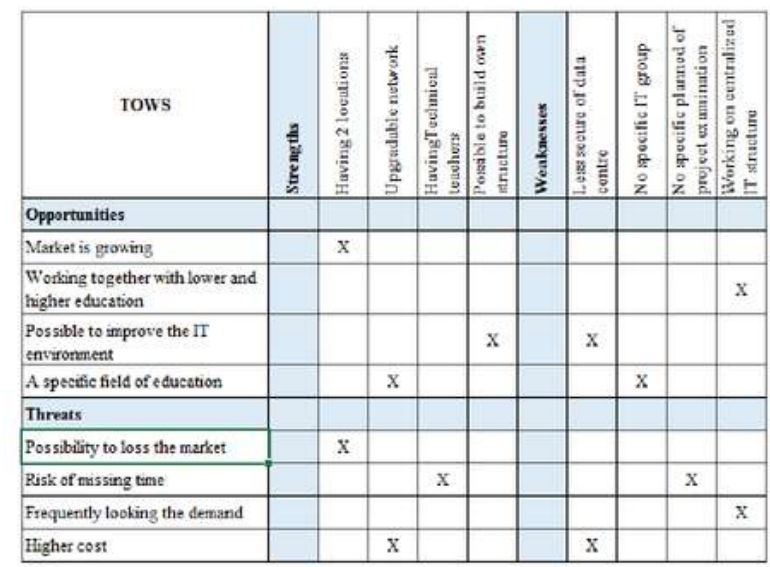

Figure 3. TOWS Matrix

TABLE III. STRATEGIC OPTIONS

\begin{tabular}{clcc}
\hline No. & \multicolumn{1}{c}{ Strategic Options } & Quadrant & Term \\
\hline 1 & $\begin{array}{l}\text { Connecting both locations, therefore it } \\
\text { is possible to increase the market. }\end{array}$ & SO & Short \\
2 & $\begin{array}{l}\text { Maximizing both locations to reduce } \\
\text { the possibility of losing the students. }\end{array}$ & ST & Short \\
3 & $\begin{array}{l}\text { Upgrading the network based on the } \\
\text { courses that ICT Lyceum offered to } \\
\text { support the lessons. }\end{array}$ & SO & Medium \\
4 & $\begin{array}{l}\text { Building the hardware and software of } \\
\text { ICT Lyceum. It is possible to run } \\
\text { separate systems from ROC } \\
\text { Leeuwenborgh. }\end{array}$ & SO & Medium \\
Improving the standardization of data \\
center to improve the quality and \\
security of data center. \\
$\begin{array}{l}\text { Working together with other } \\
\text { education to build centralized IT } \\
\text { structure. }\end{array}$ & WO & Medium \\
$\begin{array}{l}\text { Upgrading the network using a high } \\
\text { cost at the beginning. However, it } \\
\text { lowers the cost in the future by using } \\
\text { the network for at least 3 years. }\end{array}$ & ST & Medium \\
\hline
\end{tabular}


8 Improving the security of data center to prevent the more cost. Using the teachers which have experience in auditing IT. It is better

9 to have a separate group of IT which focus on improving, auditing and analyzing routinely. The risk of missing time can be

10 reduced by coordinating teachers when examination projects, therefore project done faster.

11 Using the plan to examination project 1 to prevent the risk of missing time.

12 Using IT centralized structure to

control the demand.

Using the strategies options in Table 3 , there are three (3) area recommendations: the hardware, the system, and the network scheme.

The recommended hardware can be seen below in Table 4. The proposed laboratory scheme and monitoring system for each computer, each computer will able be monitored and controlled via a central computer.

TABLE IV. RECOMMENDED HARDWARE

\begin{tabular}{cccl}
\hline Type & Category & Units & \multicolumn{1}{c}{ Specifications } \\
\hline Server & Application & 4 & 2x Intel Xeon E5-2690 2.9GHz \\
& Admin & 4 & Octa Core, 384GB (24x16GB) \\
& & RAM, SAS 3T 15K 12G \\
& & $(10 \times 300 \mathrm{~GB})$ \\
\hline PC & Laboratory & 20 & Intel Quad-Core i7 CPU with Intel \\
& & Iris Pro graphics (2,6 to 3.5GHz \\
& & Turbo, 6MB cache), 32GB \\
& & $(2 \times 16 \mathrm{~GB})$ DDR4, 500GB SSD \\
& & M.2 (2x250GB) \\
\hline
\end{tabular}

The recommended system mapped using McFarlan matrix can be seen below in Table 5 .

TABLE V, RECOMMENDED SYSTEM

\begin{tabular}{cc}
\hline Strategic & High Potential \\
\hline $\begin{array}{c}\text { Library system } \\
\text { Online Survey system }\end{array}$ & "LinkedIn" system \\
\hline Key Operational & Support \\
\hline Grade system & Monitoring system \\
& Authenticity system \\
\hline
\end{tabular}

The recommended network scheme can be seen below in Fig. 5. It is better if the routers and the firewall are supplied by Vancis' company rather than ICT Lyceum due to ICT Lyceum is understaffed to maintenance it. The firewall is used to filter and block certain websites and programs. To make it easier when upgrading or maintaining, each category of the server has its own port. Each category of the server should have at least 2 servers in each location to run back-ups. Both locations are connected using virtual local area network (VLAN). It has its own advantage, the servers can be controlled from the other location.

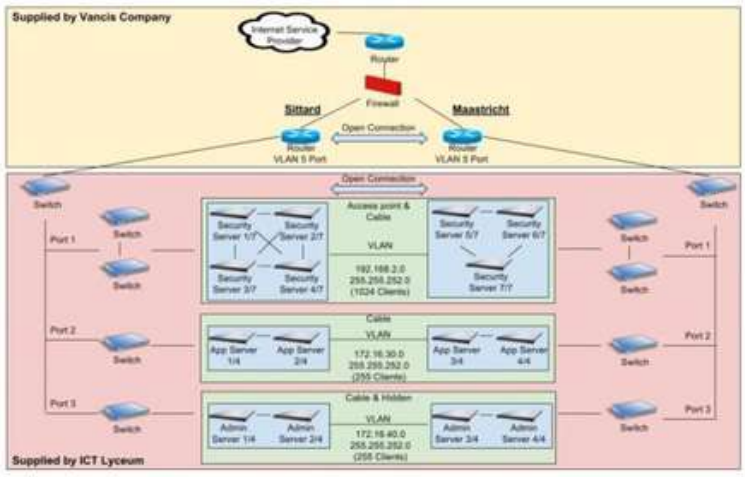

Figure 5. Recommended Network Scheme

By using the Table 5, a sequence of implementation plans can be seen in Fig. 6. The implementation plan starts from the Key Operational, followed by Strategic, High Potential, and Support. Connecting Sittard \& Maastricht in term of the network is the first thing to prepare due to the significant positive impact on the business side.

The short term of the strategic option is to maximize ICT Lyceum strengths by connecting ICT Lyceum at Sittard and Maastricht and increasing the speed of internet connection. This activity gives ICT Lyceum the same facility on both locations that means ICT Lyceum will have more rooms. ICT Lyceum also will able to run the examination in both locations. Besides, the further impact is to help ICT Lyceum accepting more students.

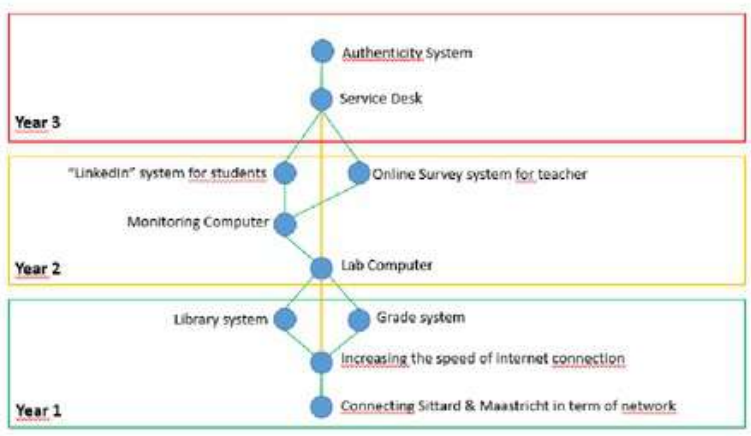

Figure 6. Implementation Plan

The medium term of the strategic option is to maximize ICT Lyceum opportunities by building the hardware, and the software to support the examinations, the projects, the lessons, and the future systems. Building the hardware refers to making servers, making laboratory with monitoring feature, and improving the standardization of the data center. The systems that are needed to build are a grade, library, "LinkedIn" for students, and online survey for teachers. The development of the systems also supported by the students. Authenticity software also needs to make sure the validation of the student work. Using this development 
plan, ICT Lyceum has a chance to work together with other institutions that do not have those systems. Besides strengthening the relationship, it also reduces the production cost of making those systems. By trying to provide complete facilities, ICT Lyceum gives a chance for students to feel the atmosphere of the education before they decided to take an education. On the other hand, ICT Lyceum has a higher chance of working together with other companies and get more project to be done by students. All of these developments should be maintained by insourcing.

The long term of the strategic option is to minimize ICT Lyceum threats by coordinating the teachers to use specific guidelines for examining project so that reduce the risk of missing time and the project will be done faster. By having coordination, it will help teachers to cooperate together. The other strategic option is by creating an independent small group that focuses on improving and auditing the information technology. Therefore, teachers will not have a double work and can continuously improve the information technology infrastructure.

\section{CONCLUSION}

The recommendation for the IT strategy implementation that can support the business goals is available. The IT strategy implementation ready to be used by ICT Lyceum to help the department reach its business goals and answer its business needs.

There are 3 recommendations for further research: (1) competitor internal and external analysis, (2) the impact of teachers' working space for their career, and (3) the whole audit of ROC Leeuwenborgh IT infrastructure

\section{REFERENCES}

[1] Y. Chan, "Why Haven't we Mastered Alignment? The Importance of the Informal Organization Structure," MIS Quarterly Executive, 2002, I(2).

[2] D. Almajali and Z. Dahalin, "Factors Influencing IT-Business Strategic Alignment and Sustainable Competitive Advantage: A
Structural Equation Modelling Approach," [Online] Available: http://www.ibimapublishing.com/joumals/CIBIMA/cibima.html.

[3] M. Broadbent and P. Weill, "Improving Business and Information Strategy Alignment: Leaming from the Banking Industry," IBM Systems Journal, Vol 32 No 1, 1993, pp 162-179.

[4] J.C. Henderson and N. Venkatraman, "Strategic Alignment: Leveraging Information Technology for Transforming Organisations," IBM Systems Joumal, Vol 32 No 1, 1993, pp 472484

[5] H. Hussin and M.A. Suhaimi, "Information Technology and Business Alignment in Malaysian SMEs," Kuala Lumpur: IIUM Press, 2011

[6] H. Hussin, M. King and P.B. Cragg, "IT Alignment and Firm Performance in Small Manufacturing Firms," Joumal of Strategic Information Systems 11, 2002, pp. 109-132.

[7] Y.E. Chan, S.L. Huff, D.W. Barclay and D.G. Copeland, "Business Strategic Orientation, Information Systems Strategic Orientation, and Strategic Alignment," Information Systems Research 1997; 8(2):125 -150 .

[8] P.G.W. Keen, "Shaping the Future: Business Design Through Information Technology," Harvard Business School Press, 1991, Boston. MA.

[9] T.C. Powell, "Organizational Alignment as Competitive Advantage," Strategic Management Joumal 1992;13(2):119 - 134

[10] P.W. Yetton, "False Prophecies, Successful Practice and Future Directions in IT Management," Proc. of the IFIP TC8 Open Conference: Business Process Re-Engineering, Information Systems Opportunities and Challenges, 1994,pp. 103-112.

[11] D. Avison, J. Jones, P. Powell, and D. Wilson, "Using and Validating the Strategic Alignment Model," The Journal of Strategic Information Systems. 13 (3), 2004, pp. 223-246.

[12] S. Chung, R. Rainer, and B. Lewis, "The Impact of Information Technology Infrastructure Flexibility on Strategic Alignment and Applications Implementation," Communications of the Association for Information Systems, 11(1), 2003, pp. 191-206.

[13] A.A. Altameem, A.I. Aldrees and N.A. Alsaeed, "Strategic Information System Planning (SISP)," San Francisco, USA: World Congress on Engineering and Computer Science, 2014 Vol. 1.

[14] L.M. Applegate, R.D. Austin, and F.W. McFarlan, "Corporate Information Strategy and Management (7th edition)," New York, NY McGraw-Hill Intemational, 2007.

[15] K. Van Tumhout, A. Coppens, S. Craenmehr and R. Bakker. "Triangulation First: Teaching Research In a Multidisciplinary Design and Engineering Environment," Int. Conf on Engineering and Product Design Education, 8-9 September 2016, Aalborg University, Denmark. 


\section{The Alignment of IT and Business Strategy at ROC Leeuwenborgh}

ORIGINALITY REPORT

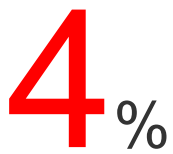

SIMILARITY INDEX
$4 \%$

INTERNET SOURCES
$1 \%$

PUBLICATIONS
$0 \%$

STUDENT PAPERS

MATCH ALL SOURCES (ONLY SELECTED SOURCE PRINTED)

$<1 \%$

$\star$ Eunike Kristi Julistiono. "Structural Pattern's Granularity Variation to Optimize a Vertical Structure", Procedia Engineering, 2017

\section{Publication}

Exclude quotes

Exclude bibliography
On

On
Exclude matches

$<5$ words 